\title{
Em busca de uma metodologia para analisar a alteridade na arte
}

Looking for a methodology to analyze alterity in art

Christine Greiner ${ }^{1}$

\section{RESUMO}

O objetivo deste ensaio é testar outros modos de formular a noção de alteridade, indagando as suas singularidades nas formas de vida e, sobretudo, nas experiências artísticas que a consideram um estado de criação. Isso porque, na arte, a diferença nem sempre gera confronto, mas instaura uma crise deflagrada pelo estranhamento daquilo que não é o mesmo e, assim, pode fazer emergirem novos caminhos de criação.

Palavras-chave: Arte. Alteridade. Corpo.

\section{Abstract}

The purpose of this essay is to test other ways to formulate the notion of otherness by investigating its singularities in life forms and, above all, in artistic experiences that consider it as a state of creation. In art, difference does not always generate confrontation, but it establishes a crisis triggered by the estrangement of what is not the same and, thus, can lead to the emergence of new ways of creation.

Keywords: Art. Otherness. Body.
1.

Professora livre-docente do Departamento de Linguagens do Corpo da Pontifícia Universidade Católica de São Paulo. ORCID: http://orcid.org/ oooo-0002-6778-516X. Contato:

christinegreiner3@gmail.com 
O tema da alteridade não é novo, mesmo assim, talvez nunca tenha sido tão colocado em evidência como na última década, com tantos confrontos políticos e a presença massiva de refugiados. Em outros momentos de crise, algumas hipóteses já foram levantadas na tentativa de desestabilizar a constituição do binômio eu e o outro. No entanto, são poucas as experiências que partem das narrativas do corpo, atravessando diferentes níveis de descrição e rompendo com as dicotomias entre natureza e cultura. É disso que se trata este ensaio: da construção de uma epistemologia que parte de narrativas nem sempre explícitas do corpo em suas relações com o ambiente.

A princípio, pode parecer que estou querendo "explicar" como o organismo funciona a partir das conexões entre corpo, cérebro e ambiente. No entanto, embora apresente algumas informações a este respeito, a minha proposta principal não é esta, e sim investigar como o corpo (e particularmente o corpo artista) lida com a alteridade a partir do movimento, antes de se constituir como um discurso.

Como será explicado no decorrer do texto, não há possibilidade de constituir uma narrativa fora da relação corpo-mente-ambiente. No entanto, a formulação discursiva tende, muitas vezes, a dicotomizar o que nunca se restringiu, de fato, ao binômio "eu e o outro", especialmente nas situações de confronto. Ao compreender melhor como este processo se dá, talvez seja possível admitir que a alteridade faz parte do fluxo da vida e não está encarcerada em dicotomias. Algumas experiências artísticas explicitam estes movimentos e por isso constituem uma parte importante da minha argumentação, como será apresentado ao final.

Para desenvolver essas ideias, antes de mais nada, é preciso abrir a pesquisa para diversas redes de conhecimento. Ao criar uma aproximação, por exemplo, entre discussões propostas por neurologistas e filósofos, nota-se que existem dispositivos de poder que agem profundamente na constituição do conhecimento e das crenças acerca daquilo que somos, do que se reconhece (ou não) como "outro", assim como, na constituição de juízos de valor. É nesses contextos que a arte tem se mostrado fundamental, na medida em que tem aptidão para simular corporalmente estados de alteridade, explicitando o modo como se constituem as conexões entre os fluxos orgânicos, a internalização dos dispositivos de poder e aquilo que se anuncia como a gênese do movimento/pensamento.

A minha hipótese é de que, ao tornar explícitas essas ações internas e as circunstâncias em que os fluxos são rompidos, poderemos refletir com mais clareza sobre nossos modos de vida, nossas escolhas e as singularidades dos processos de criação. 
Toda vez que o organismo sofre algum tipo de perturbação sente uma sensação visceral desagradável. Como se trata de uma sensação corporal, o neurologista António Damásio atribuiu a este fenômeno o nome de estado somático (soma em grego significa corpo). Além disso, ele observou que todo estado corporal "marca" uma imagem ou um fluxo de imagens como uma espécie de cartografia que o cérebro faz o tempo todo mapeando aquilo que acontece no corpo. Assim Damásio chegou ao marcador somático, cuja função seria chamar a atenção para o resultado negativo de uma ação, como uma espécie de alarme automático que anuncia um perigo para o organismo. Quando isto acontece, o corpo pode rejeitar imediatamente a situação desconfortável ou optar por outras alternativas. É importante notar que esses processos nem sempre acontecem conscientemente; por isso, algumas vezes esses marcadores somáticos não são suficientes para uma tomada de decisão, que pode exigir um raciocínio que ajude a chegar a uma decisão final. Mesmo nessas situações, os marcadores estão sempre presentes como uma ação primordial do corpo que marca uma imagem, detecta a perturbação e aponta caminhos.

Pode-se considerar, portanto, que a experiência da alteridade que lida com tudo aquilo que não é o mesmo, e sim, um estado outro, acionado por algo, alguém, alguma circunstância ou ideia diferente, constitui-se como um dos nossos principais operadores de movimento.

É o próprio Damásio quem explica que o comportamento pessoal e social acontece junto com a constituição de teorias das próprias mentes e das mentes dos outros. "Teoria", neste contexto, significa um complexo de leituras que o corpo (incluindo o cérebro, mas sem se restringir a ele) faz de si próprio, dos ambientes e de possíveis compartilhamentos. É ao marcar a imagem da diferença que o corpo se disponibiliza à mudança. Por isso toda teoria já é, inevitavelmente, uma ação.

Isso se reflete também nos modos como se organizam os três estágios do eu. A primeira fase seria o que Damásio chama de proto-eu, um tipo de descrição neural de aspectos estáveis do organismo. O produto principal desses mapeamentos que o cérebro faz do corpo são os sentimentos do corpo vivo, conhecidos como sentimentos primordiais. Na segunda fase há um pulso, através do qual este proto-eu é modificado pelas interações do organismo com outros objetos. Esses objetos podem ser literalmente objetos como compreendemos no senso comum (caneta, cadeira, bolsa, celular etc.) ou qualquer outro signo, como pessoa, imagem, ambiente 
e assim por diante. Há uma sequência narrativa de imagens que ligam esses objetos ao organismo, através de padrões coerentes que se organizam o tempo todo como mapas. Tanto os objetos como o organismo contaminam-se mutuamente, e esses mapas neurais constituem uma espécie de representação do modo como o organismo é modificado ao representar objetos durante o próprio processo de pensar. Na terceira fase, que Damásio chama de eu autobiográfico, objetos da biografia de um indivíduo criam novos pulsos ligados, momentaneamente, a um padrão coerente de larga escala. Trata-se de um estado de criação de subjetividade, habilitação para consciência e constituição de memórias, manipuladas pela imaginação e pela razão².

Além desta pesquisa de Damásio, há outros estudos que também identificaram a processualidade do "eu". Em termos filosóficos, foi Gilbert Simondon quem explicou que, ao invés de indivíduos, seríamos todos processos de individuação. Embora tenha trilhado um caminho mais voltado para os estudos da ontogênese dos seres vivos, as suas hipóteses apresentam similaridades com as pesquisas de Damásio. Segundo Simondon, os antigos gregos conheciam a instabilidade e a estabilidade, o movimento e o repouso, mas não tinham clareza em relação ao que poderia ser chamado de metaestabilidade. A seu ver, o estado metaestável seria justamente aquele que admitiria a energia potencial de um sistema e o aumento de entropia. Assim, o processo de individuação seria considerado um sistema metaestável, e o indivíduo, mais do que uma unidade ou identidade, poderia ser considerado o fruto de uma ação que ele nomeia como transdução. Esse tipo de ação transdutora acionaria um processo através do qual o ser está sempre desafasado de si mesmo e se constitui no coletivo, em relação àquilo que é díspare. Portanto, todo sistema em estado de equilíbrio metaestável pode individuar-se, mas conservará seus potenciais e devires. Nunca será fechado em si mesmo, seguindo sempre descontínuo naquilo que é outro (mundo, ambiente, pessoas, objetos etc.).

Ao invés de identidades a priori e de uma noção dicotômica de alteridade, a partir de Damásio e Simondon, as noções de eu, indivíduo e identidade tornam-se dinâmicas, porosas, inacabadas e defasadas de um self dado a priori, e passam a ser relacionadas à necessidade de repensar os coletivos evitando a noção de povo ou massa homogênea.

Um dos autores que se dedicou a este tema foi Paolo Virno (2015). Para discutir a noção de multidão, Virno também usou algumas hipóteses de Simondon e demonstrou como estas romperam com a crença generalizada de que o indivíduo é algo que
Jean-Pierre Changeux costumava dizer que o córtex pré-frontal, onde se dá boa parte dessas operações, poderia ser considerado um "gerador de diversidade", o que em inglês sugere $o$ curioso acrônimo god, a partir das iniciais de generator of diversity. 
antecede o coletivo e que, ao estar em grupo, precisa desfazer-se de algumas de suas características individuais, como se no coletivo a identidade se diluísse. Para Virno, assim como para Simondon, seria justamente o contrário. O coletivo não seria algo que atenua ou prejudica a individuação, mas sim, a sua potência. Todo indivíduo preservaria (a despeito de sua vontade) um nível pré-individual, uma espécie de fundo não estruturado que poderia gerar novas individuações. Trata-se, mais uma vez, do reconhecimento de uma instância metaestável em todo processo de individuação que defasa o indivíduo daquilo que o enclausura.

A partir desta proposta, o indivíduo seria traduzido como uma singularidade individuada, cuja instância do comum o tornaria apto a compartilhar as diferenças. Virno enfatizou o viés político desta discussão, quando escreveu o seu livro Gramática das Multidões (2001), entre outras publicações nas quais indagou como seria possível alimentar a esfera do comum que só existe quando se constitui coletivamente. Para tanto, criou pontes importantes com o pensamento marxista, sobretudo no que se refere às noções de intelecto geral (a dimensão coletiva e social do trabalho intelectual) e de trabalho imaterial (o tipo de trabalho que gera processos e não necessariamente produtos). De acordo com Virno, a partir daí poderíamos revitalizar um comum processual, onde as instâncias do individual e do coletivo apareceriam borradas o tempo todo.

Gilles Deleuze também fez parte desta discussão, uma vez que foi o primeiro a instaurar uma rica conexão entre Simondon e Baruch Spinoza, formulando, a partir daí, a noção de singularidade, que inspirou autores como Antonio Negri e Michael Hardt a conceber a diferença entre povo e multidão. De acordo com Negri e Hardt, a multidão seria um coletivo de singularidades e não uma massa homogênea, marcada por uma identidade preconcebida a partir de parâmetros como nacionalidade, território e sangue.

A vida singular ou "uma vida", como Deleuze formulou em seu último texto, seria marcada por uma especificidade vaga, em devir, nunca acabada em si mesma. Entre o murmúrio do recém-nascido e daquele que está a beira da morte, a linguagem perderia a sua onipresença para uma textualidade corpórea que sempre existiu mas, nesses estados limítrofes, parecia ganhar mais visibilidade.

Embora o modo de conceituar e gerar terminologias não seja o mesmo entre todos esses autores, há uma instância de inacabamento que marca a leitura do que se constitui como "eu" a partir dos corpos e dos ambientes. Uma espécie de precariedade da vida que não tende, necessariamente à finitude mas, antes de tudo, à coletivização. 
O pesquisador canadense Brian Massumi (2014) destaca que esta transindividualidade (uma instância coletiva tácita) está presente em todos os âmbitos, inclusive na esfera da economia. A sua leitura, de certa forma, contradiz a opinião generalizada que tem identificado com mais ênfase as atitudes narcísicas e os processos imunitários que enfraquecem a vida comunitária, fortalecendo a competitividade e todas as consequências nefastas que surgem a partir das tentativas de melhorar a empregabilidade, mesmo entre aqueles que supostamente não deveriam ser subservientes a esses dispositivos de poder, como é o caso dos artistas.

Na contramão dessas análises, Massumi identifica um plano de imanência, onde sistema econômico e sujeitos estariam reunidos em um estado funcional de indistinção entre o momento em que a ação começa e aquilo que está por vir. Ele observa o que chamará de ontopoder, que seria "o poder do devir" e "o poder de criação". Neste momento de transdução, para usar o termo de Simondon, o individual e o transindividual andariam juntos, constituindo pontes inevitáveis entre redes de afetos e racionalidades.

Deste ponto de vista, haveria todo um processo para alimentar os sistemas econômicos que não envolve necessariamente decisões conscientes. O nível não consciente poderia ser considerado também não pessoal (e sim transindividual). Por isso, a noção de self seria melhor definida como um movimento do que como uma substância. O fluxo de imagens migraria para dentro e para fora do corpo, o que faria das decisões algo que ocorre através de nós e não em nós.

É importante notar que Virno, Massumi, Simondon, Damásio e Deleuze se referem à constituição do indivíduo ou do "eu" sempre em uma instância necessariamente coletiva e descontínua, mas isto não exime os sujeitos de suas responsabilidades, como poderia parecer à primeira vista. Trata-se apenas do reconhecimento de que não há um controle absoluto e nem uma condição de individualização soberana. Massumi chega a sugerir o termo "dividualismo", que marcará, especialmente, as ações de microeconomia. É nessa instância do micro que os processos de percepção tornam-se cada vez mais significativos. Isso porque a política do dividualismo lida mais com as intensidades do que com a satisfação, criando escalas de cruzamento de sensitividades. As escolhas nunca são completamente individuais, mas em rede. Massumi arrisca dizer que o controle do individuo surfa em fluxos.

Não pretendo me estender na análise das hipóteses de todos esses autores, mas sim, chamar a atenção para uma questão que assombra o debate: se existe uma disponibilização orgânica para 
tudo aquilo que não é o mesmo e se a própria noção de "indivíduo" constitui-se a partir de uma rede de relações, o que tem atravancado o fluxo, até mesmo no que se refere a alguns processos de criação artística?

Os marcadores de territórios e os operadores de imunização

Para compreender que tipo de dispositivos agem rompendo a dinâmica metaestável da vida, recorro ao filósofo italiano Giorgio Agamben, que em 2014 encerrou os seus estudos sobre homo sacer, com o sexto volume da série, intitulado O uso do Corpo. Logo no prólogo ele sugere que somente quando o pensamento for capaz de encontrar um elemento político escondido na clandestinidade da existência singular - para além da cisão entre público e privado, política e biografia, zoé e bios -- será possível desenhar os contornos de uma forma-de-vida e de um uso comum dos corpos. Só assim "a política poderá sair da sua mudez e a biografia individual da sua idiotice" (Agamben, 2014, p. 22)

Nos últimos vinte anos, Agamben tem chamado a atenção para enunciados invisíveis que agem sobre a existência singular e suas ações políticas. Muitos autores dedicaram-se a buscar essas zonas de escuridão sugerindo diferentes diagnósticos. Segundo Agamben, uma chave importante está na noção de uso do corpo. Ele não se refere ao próprio corpo, mas ao corpo que é outro.

Este tema aparece no inicio da Politica de Aristóteles, quando este analisa o escravo. O escravo nunca pertence a si mesmo. Ele não é habilitado a produzir nada, é apenas usado no sentido prático, como se usa uma roupa ou uma cama. O escravo, além de ser propriedade do mestre, é parte dele. O uso do seu corpo o torna indistinto de quem o manipula, como um utensílio que se usa diariamente. Ao invés de usar o próprio braço, a mão ou a perna, o mestre usa o escravo. E pode fazê-lo de diversas formas, inclusive sexual. O uso deste corpo outro é, nesse sentido, sempre improdutivo. Ele não tem em vista produzir uma obra ou qualquer coisa que seja identificável. Ele age, mas não é autor de nada. O que interessa é apenas a sua ação enquanto ela acontece. A sua vida é uma vida nua (zoé), situada em uma zona de indistinção que dilui aquilo que seria ele mesmo daquele que exerce o poder.

Assim, o escravo só é incluído no âmbito da humanidade pela sua própria exclusão, como quem não tem vida própria e nem existência política. Na Grécia antiga, não havia uma separação categorizada entre sujeito e objeto, uma vez que esta dicotomia foi formulada na modernidade. Por isso, Agamben argumenta 
que não seria adequado, neste contexto, propor uma relação entre mestre e escravo, como se fosse um sujeito e um objeto. Seria mais apropriado pensar em uma mediação entre duas vidas, sendo que a vida de escravo se diluiria na vida do mestre por não ter nenhuma finalidade própria e nem ser propriamente considerado uma pessoa, mas apenas um ser vivente qualquer.

Se voltarmos para Damásio e Simondon, podemos notar que, cognitivamente, admitiu-se que o organismo nunca deveria ser visto como uma unidade substantiva, cuja identidade seria dada a priori. Também foi assumido que a noção de indivíduo é fásica, descontínua e descentrada, havendo, em todas essas constatações, o reconhecimento de uma instância coletiva no individual e de uma singularidade metaestável, mais do que uma identidade estabelecida a priori.

No entanto, a dinâmica do uso do corpo suscita outras questões. Haveria, por vezes, uma continuidade e uma zona de indistinção entre o corpo de quem tem poder e daquele que não tem. Esta conexão nada produz. O uso do outro não se configura como uma percepção da diferença que habilita uma mudança. Se as individualidades são fásicas e contam com uma pré-individualidade de devires, neste caso, a relação de poder usa a vida do outro como utensílio indistinto da sua própria vida. O escravo sequer pode ser reconhecido como um objeto autônomo. Ele representa uma mediação acionada pelo mestre que o inclui em sua vida apenas para exclui-lo. Assim, o que poderia ser a diferença mobilizadora de novos modos de individuação ou um pulso para narrativas proto e autobiográficas, traduz-se como um mecanismo de desabilitação para a vida. Ao invés de seguir os mapas cartografados pelos marcadores somáticos e a geração de diversidade, nota-se uma marcação de territórios para defender a vida própria, imunizando-a de seus antígenos estrangeiros. Trata-se de uma tentativa de privatizar e estabilizar os processos de normalização, eliminando tudo aquilo que poderia representar qualquer tipo de diferença e exterioridade.

É nesse sentido que outro filósofo italiano, Roberto Espósito (2011), dirá que a imunidade é um dos principais paradigmas que enfrentamos hoje. Em seu livro Immunitas, o "outro" seria apenas uma dose pequena de veneno internalizada para nos imunizar do coletivo, seguindo a lógica da vacina que inclui para excluir.

É possível defasar a vida destes dispositivos

de poder através da arte?

O que diferencia as experiências artísticas é que a ação dos marcadores somáticos vai além do acionamento de movimentos porque 
deixa de ser uma ação habituada e invisível. Ela se torna a ação primária da criação e desestabiliza a relação um e outro, porque nem um nem outro são dados a priori. São processuais, metaestáveis, dinâmicos e sistêmicos.

No entanto, assim como a plasticidade orgânica é camuflada e interceptada por dispositivos de poder como na relação entre mestre e escravo, há também mudanças nos processos de criação que, muitas vezes, são transformados em estratégias criativas subservientes aos dispositivos de poder gerados pelos contextos político-econômicos.

O que tem acometido artistas no mundo todo é a diferença temporal entre estratégias criativas de entretenimento e os processos de criação, como discute Pascal Gielen (2015). Ao comprometer o tempo da criação, ela transforma-se em mera exibição. Além disso, arrisco dizer que há também um outro problema: as estratégias criativas (que não se constituem como processos de criação) lidam com o mesmo e não com aquilo que poderia desestabilizar padrões vigentes (certezas, movimentos, narrativas e assim por diante).

Talvez seja esta a encruzilhada a ser enfrentada, não apenas pelos artistas, mas por todas as atividades que lidam com produção de conhecimento. Como seguir acreditando e acionando os processos de mudança?

Massumi afirma que faz parte do neoliberalismo um certo tipo de movimento que morre do seu próprio sucesso. Por isso, o sucesso micropolítico é, muitas vezes, a falha macropolítica, e isso pede, necessariamente, pela reinvenção de coletivos. Se os processos imunitários prejudicam as alianças, por outro lado, há uma dimensão estética da vida que insiste, produzindo uma rede de possibilidades.

Talvez possamos pensar o mesmo em relação à arte. Vigora uma macro produção artística, coerente com as expectativas do mercado e com tudo aquilo que já é familiar e propenso a uma boa receptividade. Mas, simultaneamente, há uma micro produção artística, suscetível às desestabilizações, ao risco e a tudo aquilo que tende a ser visto como falha - nem um nem outro, mas a negação desta mesma dicotomia.

Nesse sentido, fica claro que as manifestações políticas que têm instaurado o confronto corporal nas ruas não são similares aos processos de criação artística. A diferença está, justamente, no modo de compreender a alteridade. No caso dos protestos, a dicotomia e as identidades dadas a priori são o ponto de partida, que, por sua vez, acaba gerando a negação ou exclusão do outro, como se a única possibilidade de sobreviver fosse aderir à lógica da imunização. No entanto, os processos de criação artística 
(referentes à microprodução) são alimentados pela alteridade, no sentido de fortalecer a aptidão para desestabilizar a dicotomia e acionar a crise sistêmica que os constitui. Não se trata de um ou outro, mas de explicitar a descontinuidade e alimentar a transindividualidade que não gera uma identidade estagnada.

A criação artística não tem o compromisso de promover mudanças sociais ou políticas. Mas, ao dar visibilidade aos estados de crise, explicita questões nem sempre visíveis na vida cotidiana. Assim, instauram-se conexões que podem desestabilizar hábitos e crenças e apontar possibilidades. É nesse sentido que o estado de alteridade pode se traduzir como um estado de criação. Dois exemplos que evidenciam isso são os nomadismos involuntários e os estados de exceção. Ambos são absolutamente ambíguos. Por um lado, parecem imobilizar todos os processos, mas por outro, como sugere o filósofo brasileiro Vladimir Safatle (2015), é o corpo desamparado que nada tem a perder. Ele é justamente aquele que pode agir politicamente.

Para Safatle, assim como para Butler e Athanasiou (2013), o desamparo cria vínculos por despossessão. Ele despossui o sujeito dos predicados que o identificavam. Um corpo político produzido pelo desamparo é um corpo em contínua despossessão e des-identificações de suas determinações. É assim que o desamparo produz corpos em errância que podem gerar mudanças.

Nesse sentido, a experiência artística poderia ser considerada um procedimento de desamparo cognitivo que, ao des-identificar a si mesma e aos outros, afirma-se no âmbito da vida comum.

De certa forma, foi o que presenciamos entre as décadas de 1960 e 1970 com tantas manifestações artísticas mobilizadas pela necessidade de politizar a vida, constituir comunidades e redes de resistência. No Brasil, durante essas décadas começaram a surgir as primeiras experiências que apontavam para as artes contemporâneas, que buscavam constituir-se a partir de práticas e não de modelos dados a priori. Tendo em vista a situação política da época, marcada pelo regime militar, não havia apoio financeiro para as artes, muito menos para manifestações que poderiam, ainda que vagamente, ser consideradas subversivas. Assim, des-identificar a si mesmo poderia ser interpretado como agir coletivamente contra uma situação extrema. Mudar os hábitos alimentares, a crença religiosa, usar drogas, testar novos treinamentos seriam estratégias para constituir um outro corpo, apto a agir (ou decidido a não agir) e, assim, mudar.

Imersos na segunda década do novo milênio, enfrentamos muitos dos dispositivos de poder destacados no decorrer deste texto. Ainda não se pode dizer que exista, de fato, um mercado 
para as artes do corpo no Brasil, embora tenham sido criados instrumentos de apoio. Ocorre que alguns desses instrumentos têm se mostrado perversos ao impor prazos curtos para criação e exigir resultados quantificáveis, alimentando a competitividade e tornando frágil a formação de comunidades, na medida em que são sempre descontinuados, sem fazer parte de uma política cultural.

Talvez os processos que consigam escapar disso sejam aqueles que alimentam uma micropolítica de ações, optando por se expor à estranheza que mobiliza e marca somaticamente a diferença. 


\section{REFERENNCIAS}

AGAMBEN, Giorgio. L'Usage du Corps, homo sacer IV, 2, trad. Joël Gayraud. Paris: Seuil, 2015.

AGAMBEN, Giorgio. Profanações, trad. Selvino J. Assmann. Boitempo, 2015.

BUTLER, Judith; ATHENA, Athanasiou. Dispossession: the performative in the political. Cambridge: Polity Press, 2013.

CASTRO, Eduardo Viveiros de. Metafísicas Canibais. São Paulo: $\mathrm{N}-1,2015$.

CHANGEUX, Jean-Pierre. L'Homme Neuronal. Paris: Fayard, 1983. DAMÁSIO, Antonio. O mistério da Consciência, do corpo e das emoções ao conhecimento de sim, trad. Laura Teixeira Motta. São Paulo: Companhia das Letras, 2000.

DELEUZE, Gilles. "L'immanence: une vie...", Philosophie n 47, 1995. Espósito, Roberto. Immunitas, the Protection and Negation of Life, trad. Timothy Campbell. Cambridge: Polity Press, 2011.

GIELEN, Pascal. Criatividade e Outros Fundamentalismos, trad. Sharine Mello. São Paulo: Annablume, 2015.

GREINER, Christine. O Corpo, pistas para estudos indisciplinares. São Paulo: Annablume, 2005.

GREINER, Christine. O Corpo em Crise, novas pistas e o curto-circuito das representações. São Paulo: Annablume, 2010.

GREINER, Christine. Leituras do Corpo no Japão e suas diásporas cognitivas. São Paulo: N-1, 2015.

GREINER, Christine. "Alteridad como estado de creatión" in Pereze, Victoria Royos e Diégo Aguilló (eds). Componer el Plural. Barcelona: Mercat des Flors, 2016, p. 319-349.

KRAUSS, Rosalind. A Voyage on the North Sea: Art in the Age of the Post-Medium Condition. New York: Thames \& Hudson, 2000. MASSUMI, Brian. The power at the end of the economy. Durham: Duke University Press, 2014.

NEGRI, Antonio; HARDT, Michael. Multidão, guerra e democracia na era do império, trad. Clovis Marques. Rio de Janeiro: Record, 2004.

SAFLATE, Vladimir. O circuito dos afetos, corpos políticos, desamparo e o fim do indivíduo. São Paulo: Cosac Naify, 2015.

SIMONDON, Gilbert. L'individuation psychique et collective. Paris: Aubier, 1989.

VIRNO, Paolo. Gramática das Multidões, para uma análise das formas de vida contemporâneas, trad. Leonardo Palma. São Paulo: Annablume, 2015. 